\title{
Mary Patrice Erdmans and Timothy Black: On Becoming a Teen Mom: Life Before Pregnancy
}

\author{
University of California Press, Oakland, CA, 2015, 344 pp, ISBN: 9780520283428
}

\author{
Stephen William Risk ${ }^{1}$ (D)
}

Received: 31 May 2015/Accepted: 2 June 2015/Published online: 27 June 2015

(C) Springer International Publishing 2015

On becoming a teen mom: life before pregnancy, presents a unique perspective on the subject of teen motherhood in America. Erdmans and Black take one of the most important issues in society today, one that has been used both socially and politically to bolster numerous agendas and legislation, and approach it from a fairly novel direction. The authors choose to focus not on the culpability of the mothers for their pregnancies and lifestyles but on the familial, social, educational, and economic environments that these girls lived in both before and after becoming pregnant. Thus, they seek to understand the reasoning behind the decisions these young mothers make by considering the motivations and pressures they were facing at the time of their pregnancy decisions and those that they may continue to face in their daily lives. The methodology for achieving this understanding is presented in the book's introduction and involves presenting the life stories of several of the teen mothers in conjunction with other data collected from the study to support the various arguments that the authors present.

The first chapter of the book highlights how teen motherhood has become such a hot topic in today's social and political arenas. The authors imply that teen pregnancy is an incredibly useful tool for politicians to use in bolstering their political image because it resonates on two basic fronts: it promotes religious and moral values of the "nuclear family" as American ideals and it confronts issues of welfare spending by emphasizing that lower teen birth rates would mean lower welfare expenditures. They suggest that both of these ideas stem from an undercurrent

Stephen William Risk

swrisk@indiana.edu

Indiana University, Bloomington, Bloomington, IN, USA of racial fear and segregation. The issue of teen pregnancy is used as a platform to discuss welfare reform and urban crime rates. In the past, the majority of Americans were concerned with the growth, or "fertility," of the underclass because it was seen as a threat to the established order or way of life. As a result, poverty-stricken communities have been prime targets for political and social advocates to use as examples of the importance and necessity of the policies proposed for poorer, ethnic communities (e.g., crime, teen pregnancy, truancy, welfare dependence). This is said to have helped fuel a racial undercurrent of fear in white majorities regarding the financial and moral stability of their country. Although the evidence shows that teen pregnancy rates are decreasing, these ideologies still affect the policies being written and enforced today. It is further suggested that these ideologies of "blame and shame" are being used as distractions from more pressing and less easily targeted social issues, such as poverty, lack of funding within the local education system, or gender and racial inequality. It is apparently easier to focus on the symptoms of these larger issues, such as crime rates and teen motherhood, than these causal issues that are in the public spotlight. The authors also discuss the selection of 108 racially and socio-economically diverse teenage mothers from Connecticut who comprised the research sample interviewed for their study.

In the next chapter, the issue of young mothers, also known as "children having children," is addressed in the context of child sexual abuse. While clearly supportive of protecting young children from abuse, the authors acknowledge the inherent difficulties in studying this population because the abusive situations are often complex and not easily categorized. The authors proceed to challenge three specific explanations for teen motherhood: poor parenting, high fertility rates within Latino communities, and 
predatory men. The poor parenting explanation suggests that parents were either delinquent or too permissive, which caused the teen mothers to seek love and affection in other ways. However, the interviews of two girls, who had children when they were 12 and 13, introduce an explanation that seems to be the exact opposite of the poor parenting explanation. Their childhood was characterized by strict parental figures and described as confining. They reacted by rebelling which resulted in their teen pregnancies. It was suggested that the parents, many of whom were immigrants, had adopted a strict parenting style in reaction to fears regarding neighborhood safety as well as to cultural identity. While the authors admit that parental delinquency and abandonment may be a factor in teen pregnancy, their sample suggests the opposite, that a strict parenting style plays an equally important role. The authors also note that the extended family, including parents, grandparents, cousins, aunts, and siblings, were generally supportive of the teen mothers, even if they did not approve of the pregnancies. This was also emphasized in the second explanation, which focuses on overt racial biases toward poverty and urban living. Some social advocates and politicians claim that Latino communities are producing too many children in need of government support. This same claim has been made against immigrant groups throughout this nation's history, and it continues to be made toward current minority (black) communities as well. However, the data from this research reveals that the birth rates among white, black, and Latino teens are only marginally different and that teen births represent a very small amount of financial burden on the welfare system. The third explanation of teen pregnancy being challenged by the authors is predatory men and is discussed in great detail. While statutory rape laws are useful in certain cases, the authors argue that they have both too great and too narrow a reach to be effective. Statutory rape laws were created as part of a welfare initiative to force men to take responsibility for having sex with much younger women. However, the leniency as to the limits and enforcement of these statutes makes them too fluid and arbitrary to address the issues associated with predatory men. Rather, their breadth and scope makes them quite useful as a tool against minorities, where teen pregnancy is more likely to occur due to poverty and its effects. At the same time, the laws are also too narrow because they can effectively restrict teen sexual behavior that otherwise would be perceived as appropriate. In some cases, young teens who are more mature than their counterparts, may consciously choose to have children with older men who are able to provide for them and their children. Statutory rape laws focus strictly on age, without considering the possible maturity or situational variances that could occur. At times, these laws are even counterproductive because incarcerated fathers are not able to support their family financially. In many cases, the poorer communities seem to be overrepresented in the enforcement of these laws and with the removal of potential financial providers; as a result, these laws serve to exacerbate the problem that they were intended to prevent. In addition, the social stigma of a sexual abuse conviction brings shame and helplessness to the family. As suggested above, the statutory rape laws seem to be more used in poorer minority communities. This is believed to be because social workers and welfare caseworkers are more prevalent in poorer communities and they are more likely to report abuse than in other communities where social service is less prevalent. Thus, in more wealthy areas where social services are less visible, pregnant teens are usually counseled against revealing abuse by family members eager to avoid personal and family embarrassment. These teens also have more access to birth control and contraception. The authors use all of these points to convey that statutory rape laws do less to protect young girls from abuse than to incarcerate minority males.

In the next chapter, violence against women is addressed with an emphasis on how it can shape the lives and decisions of teen mothers. Several stories about young teen mothers are presented. The stories looked at how girls raised in sexually and physically abusive homes, where family members were often the abusers, coped with the emotional, physical, and mental effects of that abuse. A reoccurring theme among these life stories was that the abuse occurred frequently, from multiple sources, and was mostly ignored by parental figures. The mothers tended to be unwilling to go into detail about the abuse, minimizing it as an event that just occurred to them. The damage to the confidence and self-worth of these chronically abused young women seems to have led them into abusive relationships, drugs and alcohol use, promiscuity and sex work, and eventually pregnancy and motherhood. Yet, most of these women did not see themselves as victims. Though they recognized that the abuse was wrong, they viewed it as something they had to endure to navigate the harsh realities of their lives. The authors attribute these attitudes to the gender inequalities that still exist within our mostly patriarchal society. They contend that, despite some progress in gender inequality, there is still a prevalent undercurrent of male entitlement to women's bodies for sexual entertainment. This is especially prevalent within the media, where women are repeatedly shown through advertisements that their personal worth is based on their ability to be beautiful and attract a male. Men are praised for their sexual prowess and their ability to assert dominance over others. While currently less overtly accepted or publically acknowledged, these ideas still shape the attitudes of young boys and girls. The stories also reveal the continued pervasiveness of women's objectification in society. It is apparent that these girls were used and abused, both physically and sexually, by many of the men with 
whom they have close relationships. Many times, the choice to have a child is a turning point because they become someone who has achieved the respectable and noble role of motherhood. Raising children provides the stability and recognition these girls are often seeking. Unfortunately, their ambitions are often thwarted by the very same culture that pushed them toward that goal in the first place. This is evident in the stories that had examples ranging from mothers who continued to put up with infidelity and abuse because of their financial dependence on the fathers to girls whose fathers rejected them and referencing their social situations as justification. In short, this chapter emphasizes the power of the teen mother's environment in pushing them toward a decision to have children.

The next chapter emphasizes the effects of education on teen motherhood. Specifically, it addresses the issues of underfunding of local education as well as the schools' failure to meet the special needs of teen mothers. Some of their special needs are associated with their history of physical and sexual abuse and the resultant emotional, physical, and mental effects. These issues include a lack of emotional connectivity, cognitive disability, frequent changes in schools, and changes in educational styles due to financial needs or attempts to escape abuse. Another related issue is that a lack of support structures can cause teen mothers to fall behind in their schoolwork and eventually drop out of school. This is especially prevalent in schools within poorer communities that lack the resources to meet students' needs. Teen mothers are often held back or placed in special education courses, which further alienates them from their peers and leads to higher rates of dropping out. In some cases where the violence of a teen mother's life begins to express itself in the school, many teachers and administrators will enact measures such as suspensions that may end up improving the learning environment of the students overall but exclude the teen mother. In some cases, teen mothers left school to seek employment as a means to provide for themselves and their children. However, it is interesting to note that teen mothers, when compared to their counterparts of similar social and economic standing, were slightly more likely to pursue education (such as a diploma or GED). This contradicts the notion that teen pregnancy is detrimental to educational goals and prevents teen mothers from achieving educational success. Although it is surprising that teen pregnancy does not seem to have as much of a negative effect on education as is popularly believed, the evidence does not support the notion that it is helpful.

The next chapter discusses the issues of contraception and abortion in regard to teen motherhood. The stories shared here are from teen mothers who would be considered "good girls" from middle and upper class homes with traditional nuclear families. In addition, they have financial stability, access to adequate education, and no history of any form of abuse or neglect. These are mothers who were expected to finish school and further their education and career goals. Almost all of these teen mothers had pregnancies categorized as unintentional. The issues raised in this chapter include the stigma of teen motherhood, inadequate contraception education, and policies regarding female sexual health. These teen mothers feared the social stigma of teen motherhood from their families and peers. Many hid their condition for long periods of time, which resulted in them not receiving proper prenatal care and caused risks to their children. Much of this stigma occurs due to moral ideals that are not only propagated by communities as a whole, but are specifically used to limit sex and contraception education. The authors discuss contraception in some detail with a focus on two varieties that are differentiated by who directly controls their use. Females have control of birth control pills or vaginal rings and males have complete control of condoms. It was noted that contraceptive methods that are controllable by women are more difficult to obtain than those controlled by men. Current policy changes that seek to restrict a woman's control over her own sexuality threaten to make it even harder for women to be in control of their own birth control. Education can be helpful here because, while it is easy for men to obtain contraception, it is difficult for some woman, who want their partner to use contraception, to discuss this issue with him. It becomes even more difficult when contraceptive education is limited to abstinence and/ or completely ignored. Thus, many teen women feel they must rely on their partner's willingness and knowledge to use contraception. Unintended teen pregnancies frequently occur when misinformation about the use or effectiveness of contraception leads to it not being used. The authors then turn their focus to a discussion of abortion and the issues of availability of proper medical care and abortion clinics for teen mothers. Specifically, they discuss the countless number of laws that have attempted to remove or limit the option of abortion for teen mothers. These laws frequently require parental consent which, given the stigma of teen pregnancy, may discourage young teen mothers who wish to keep their pregnancy a secret from their families. They emphasized that policy makers as well as society in general seem to stand united in their opinion that teen motherhood is morally wrong, while at the same time actively fight against the abortion option. The result is a further limitation on the options for teens who unintentionally become pregnant. This section reemphasizes the influences of policy makers and society in general in limiting a teen mother's choices.

The information presented in this book is informative and provides insight into what teen mothers experience 
from their childhood through pregnancy as well as the experiences of being a teen mother. The more specific discussions of major issues that affect the lives of teenage girls and their decisions to have children also provide valuable background information. Unfortunately, this is only the beginning of the discussions necessary to address teen pregnancy. A crucial next discussion must address the issues presented in this book in a positive manner that will further the understanding of how to minimize the factors known to increase the likelihood of teen pregnancy. This book fails to consider this necessary step in addressing teen pregnancy. This failure is understandable given the incredible complexity of the interrelated factors that likely affect teen pregnancy rates. In order to come to terms with the underlying causal issues, many of the fundamental ills of society would need to be considered. This is an overwhelming task that will require many future studies and associated books. However, this text does an amazing job of introducing those issues and helping to dispel many of the myths of teen pregnancy. Issues regarding using teen pregnancy as a front for enacting socially racial and patriarchal policies are thoroughly addressed, and the voices of teen mothers are presented in a way that is both informative and empathetic. It is easy to disparage particular groups of people because they violate commonly accepted moral beliefs. However, by humanizing these teen mothers through their stories, the book reminds readers that they are just ordinary people who happen to have become teen mothers. It is through this lens that potential understanding and acceptance may be gained. The findings discussed in this book would be more robust and generalizable if the original study were expanded in number and variability of the subjects. It would be interesting to see if the findings were generally similar. If data collection could be expanded to different regions of the country, the possibility of variability between regions could be studied. In the end, the book reveals the important role of research in understanding phenomena that people believe they already understand, and how empirically based findings can make a difference.

Conflict of interest None. 